\title{
Development and Application of Polydimethylsiloxane (PDMS)-based Passive Air Sampler to Assess Personal Exposure to SARS-CoV-2
}




\section{S1. Details of Drum Experiments}

\section{S1.1. Ф6 Propagation}

Pseudomonas syringae pv. phaseolicola strain HB10Y, American Type Culture Collection (ATCC) \#21781, was used as the bacterial host to propagate $\Phi 6$.(1) A single colony of $P$. syringae was picked from Luria Broth (LB) agar plates ( $15.0 \mathrm{~g} / \mathrm{L}$ agar), two days post streaking, suspended in LB media, and incubated overnight at $25^{\circ} \mathrm{C}$. The soft agar overlay plaque assay method was used to propagate working stocks of $\Phi 6$, on a lawn of $P$. syringae, and quantify their infectious concentrations.(1-3) To harvest phage lysate, soft agar of plates with 20-200 well defined plaques was scraped into a sterile $50 \mathrm{~mL}$ conical tube, resuspended in $4 \mathrm{~mL}$ of LB media, vortexed, centrifuged at 1200 RPM for 10 minutes and supernatant was passed through a $0.22 \mu \mathrm{m}$ syringe filter. Stocks of phage lysate containing $10^{6} \mathrm{PFU} / \mu \mathrm{L}$ were used in subsequent rotating drum experimentation.

\section{S1.2. Rotating Drum Experiments}

The rotating drum is $30.5 \mathrm{~cm}$ in outer diameter and $61 \mathrm{~cm}$ in length with a total volume of 44.5 L. The drum was attached via belt to an electric motor, rotating at a constant speed of $\sim 2.9$ RPM to maintain suspension of aerosols.(4) Probe and sampling ports were placed on the double sealed ball bearing which comprises the non-rotating part of the drum. The temperature and relative humidity inside the drum were monitored with a Temp/RH probe (Onset HOBO MX1101). Two inlet ports were installed to introduce aerosols and make-up air separately. The nebulizer was supplied with filtered house air (Whatman ${ }^{\mathrm{TM}}$ Carbon Cap capsule filter). Multiple sampling ports placed on the other end of the drum were used for insertion of PDMS tube pieces via syringes, filter-based active sampling, monitoring of aerosol size distribution, and exhaust. The exhaust flow was also passed through a HEPA filter to prevent the virus release.

Before each experiment, the drum was cleaned with $90 \%$ ethanol and purged with filtered house air until no aerosols were detected. The nebulizing medium, which included phage, artificial saliva, and $\mathrm{CaCl}_{2}$ was kept on ice and sampled prior to aerosolization to determine the total number of viral genome copies. Test aerosols were generated by a 6-Jet Collison Nebulizer (BGI) at 20 psi and were introduced into the drum for 10 seconds. The exhaust was open during aerosolization to prevent pressure build-up inside the drum. After aerosolization, the drum was sealed and mixed for $3 \mathrm{~min}$ to obtain homogeneous aerosol prior to sampling. Multiple $2.5 \mathrm{~cm}$ long PDMS tubes (SILASTIC ${ }^{\mathrm{TM}}$ Laboratory tubing, $0.2-\mathrm{cm}$ O.D.) were inserted into the drum through the sampling ports and were replaced after different periods of exposure, allowing various exposure durations in different exposure conditions. PDMS samples were collected in triplicate for each exposure. The drum air was withdrawn every 30 min onto a $37 \mathrm{~mm}$ gelatin filter in a cassette (SKC Ltd) at a rate of $1.5 \mathrm{~L} / \mathrm{min}$ for $2 \mathrm{~min}$ via an active sampling pump (GilAir Plus). The concentration and size distribution of drum aerosols were monitored before and after each active sampling using an airborne particle counter (Met One HHPC-6). To balance for air loss during sampling, $2 \mathrm{~L} / \mathrm{min}$ make-up air was supplied into the drum and the excess air was vented.

Two experimental runs were conducted in this study, generating 18 passive PDMS samples (triplicates from 6 exposure conditions) and 4 active filter samples for run \#1 and 24 passive samples (triplicates from 8 exposure conditions) and 4 active samples for run \#2. All samples were stored immediately after collection at $-80^{\circ} \mathrm{C}$ prior to RNA extraction and quantification. 


\section{S1.3. Estimation of Cumulative PDMS Exposure to Viral Aerosols}

The viral aerosol concentration in the drum is subject to exponential decay.

$$
N=N_{0} e^{-k t}
$$

where $N_{0}\left(\# / \mathrm{m}^{3}\right.$ of air) is the initial aerosol number concentration, $N\left(\# / \mathrm{m}^{3}\right.$ of air) is the aerosol number concentration after time $t(\mathrm{hr})$, and $k\left(\mathrm{hr}^{-1}\right)$ is the first order aerosol decay constant. The decay constants for aerosols with different sizes were calculated and shown in Figure S3.

Based on the aerosol decay curve, the cumulative exposure to viral aerosols with a certain aerosol size during $\mathrm{t}=t_{1} \sim t_{2}$ can be calculated as the integral of aerosol number concentrations versus exposure duration.

$$
\int_{t_{1}}^{t_{2}} N_{0} e^{-k t} d t=\left.\frac{N_{0}}{-k} e^{-k t}\right|_{t_{1}} ^{t_{2}}
$$

The aerosol exposure measured by count were further converted to an exposure expressed by aerosol mass assuming spherical particles and unity particle density $\left(\right.$ i.e., $\left.\rho=1 \mathrm{~g} / \mathrm{cm}^{3}\right)$. The cumulative exposure to aerosols was calculated as the sum of time-integrated mass concentrations of aerosols with different sizes.

$$
\bar{C}_{P M} t=\sum_{i=1}^{N} M\left(D_{p i}\right)=\sum_{i=1}^{N} \rho \frac{1}{6} \pi D_{p i}^{3} N\left(D_{p i}\right)
$$

where $D_{p}$ is the aerosol diameter, $N\left(D_{p}\right)$ and $M\left(D_{p}\right)$ are the time integrated number and mass concentrations, respectively, for aerosols with size of $D_{p} . \bar{C}_{P M}\left(\mu \mathrm{g} / \mathrm{m}^{3}\right.$ of air) is the time-weighted average mass concentration of aerosols suspended in the drum air.

The RNA concentration contained in the aerosol ( $C_{R N A_{P} P M}$, in unit of copies $\left./ \mu \mathrm{g}\right)$ was then determined from active samplers.

$$
C_{R N A_{-} P M}=\frac{m_{R_{\text {RA_f }} \text { filter }}}{C_{P M_{\_} \text {sampling }} V_{\text {air }}}
$$

where $m_{R N A_{-} \text {filter }}$ (copies) is the RNA amount measured from the gelatin filter, $C_{P M_{-} \text {sampling }}$ $\left(\mu \mathrm{g} / \mathrm{m}^{3}\right.$ of air) is the average mass concentration of suspended aerosol in the drum air during active sampling, and $V_{\text {air }}\left(\mathrm{m}^{3}\right)$ is the air volume passed through the gelatin filter.

The uptake rate of viruses by PDMS can be expressed as

$$
R=\frac{m_{R N A}}{\bar{C}_{R N A} t}=\frac{m_{R N A}}{C_{R N A \_P M} \bar{C}_{P M} t}
$$

where $m_{R N A}$ (copies $/ \mathrm{cm}^{2}$ of PDMS) is the amount of RNA accumulated on unit area of PDMS, which was adjusted for recovery of virus from PDMS. $\bar{C}_{R N A}\left(\operatorname{copies} / \mathrm{m}^{3}\right)$ is the time-weighted average virus concentration in the drum air, and $t(\mathrm{hr})$ is the exposure duration. Assuming that the virus concentrations in aerosols with various sizes are identical and remain constant during the whole experiment period, the viral RNA in the drum air follows the same decay pattern as the aerosols. Therefore, the cumulative exposure to virus, i.e., $\bar{C}_{R N A} t$, is equal to $C_{R N A \_P M}$ times the cumulative exposure to aerosols $\bar{C}_{P M} t$. 


\section{S2. Viral Quantification and Recovery}

\section{S2.1 PDMS Pad Synthesis}

Using the 184 Silicone Encapsulant Clear $0.5 \mathrm{~kg}$ kit (Dow Sylgard ${ }^{\mathrm{TM}}$ ), PDMS was syringed onto a substrate and desiccated overnight to remove bubbles, creating a smooth surface for sorption. Elevated open covers were added to the PDMS pads to prevent direct contact with other surfaces but allow for aerosol diffusion and droplets to land on the PDMS surface. PDMS pads were then secured in Fresh Air Clips for personal sampling.

\section{S2.2 Quantification of $\Phi 6$ by RT-ddPCR}

Ф6 RNA was quantified in the artificial saliva used for aerosol generation in the nebulizer as well as passive air samplers (PDMS sorbent tubes) and active air samples (gelatin filters). RNA extraction used the Quick-RNA Viral Kit (Zymo Research) and eluted into15 $\mu \mathrm{L}$ of RNase free water. RNA extraction of the $\Phi 6$ nebulizing solution was completed by adding $10 \mu \mathrm{L}$ of sample into the lysis step. Gelatin filters were dissolved in RNase free water $(100 \mu \mathrm{L})$ and added to the lysis buffer while PDMS sorbent tubes were placed directly into lysis buffer. The extraction protocol was completed according to the manufacturer's instructions. Total viral RNA was quantified using droplet digital Polymerase Chain Reaction (ddPCR), with the One-Step RTddPCR Advanced Kit for Probes (BioRad) and the manufacturer's recommended thermocycling protocol with an annealing/extension temperature set to $60^{\circ} \mathrm{C}$. Samples were run in duplicates with $5 \mu \mathrm{L}$ of RNA template per sample replicate. A previously developed primer probe set was used for $\Phi 6$, the sequences are as follows: forward primer sequence 5'TGGCGGCGGTCAAGAGC-3', reverse primer sequence 5'GGATGATTCTCCAGAAGCTGCTG-3', and probe 5'-FAMCGGTCGTCG/ZEN/CAGGTCTGACACTCGC- IABkFQ -3'.(5-7)

\section{S2.3 Quantification of SARS-CoV-2 by RT-ddPCR}

SARS-CoV-2 RNA concentrations were evaluated for PDMS $\left(4.10 \mathrm{~cm}^{2}\right)$ contained in Fresh Air Clips. PDMS pads were removed from the substrate with forceps, sectioned into strips, directly placed into lysis buffer tubes and extracted using the Quick-RNA Viral Kit (Zymo Research) with an elution volume of $15 \mu \mathrm{L}$. The One-Step RT-ddPCR Advanced Kit for Probes (BioRad) and its protocol was used for ddPCR analysis with $5 \mu \mathrm{L}$ of RNA template per sample, and an annealing/extension temperature of $55^{\circ} \mathrm{C}$. The N1 assay of the 2019-nCoV CDC Kit (Integrated DNA Technologies) was used for quantification of SARS-CoV-2 from field samples; sequences as follows: forward primer sequence 5'-GACCCCAAAATCAGCGAAAT-3', reverse primer sequence 5'-TCTGGTTACTGCCAGTTGAATCTG-3', and probe 5'- FAMACCCCGCAT/ZEN/TACGTTTGGTGGACC-3IABkFQ-3'. Sample extracts were run in duplicates and with negative and positive controls of nuclease free water and SARS-CoV-2 standards (BioRad), respectively.

To confirm the SARS-CoV-2 positivity of Fresh Air Clip samples, two criteria were applied: 1) both replicates of RNA extracts per sample were required to be positive and 2) copies of SARS- 
CoV-2 viral RNA were above the method detection limit (MDL) of 6 copies/clip following

154 ddPCR analysis.

\section{S2.4 Viral Recovery from PDMS}

The recovery of SARS-CoV-2 from the PDMS pad was determined. Wastewater previously detected to contain SARS-CoV-2 virus was diluted, loaded onto PDMS pads at seven different concentrations (6 to 1420 RNA copies) in duplicate and dried at room temperature for 30 minutes in a biosafety cabinet. RNA was then extracted from the PDMS pads and liquid samples containing equivalent amounts of virus using the Quick-RNA Viral Kit (Zymo Research) and quantified via ddPCR. The recovery for SARS-CoV-2 RNA from the PDMS pads was determined to be $45 \% \pm 8 \%$ SE (95\% CI: 30 to $60 \%$ ) (Figure S2). This recovery experiment was replicated using $\Phi 6$, the surrogate for SARS-CoV-2 used in rotating drum experiments. Phage was diluted and the decreasing concentrations of $\Phi 6$ were loaded onto PDMS pads. Liquid dilutions of $\Phi 6$ as well as the PDMS pads loaded with corresponding dilutions of $\Phi 6$ were extracted and quantified. Extraction of $\Phi 6$ from PDMS was near unity with average recovery of $131 \% \pm 19 \% \mathrm{SE}$, and a $95 \%$ confidence interval for the slope of 80 to $180 \%$. Additionally, experimentation to determine the potential decay in virus recovery over time (the five-day sampling period of Fresh Air Clips) was conducted. SARSCoV-2 and $\Phi 6$ were independently loaded onto PDMS pads and dried for 30 minutes. Viral RNA was extracted from the PDMS pads on days 1, 3, and 5 following viral loading onto the pads and quantified using ddPCR. These results yielded no observable decrease in RNA concentration for SARS-CoV-2 or $\Phi 6$ recovery from the PDMS pads over the five-day period at $50 \%$ RH.

\section{S2.5 SARS-CoV-2 ddPCR MDL Determination}

Our analysis to estimate the MDL for SARS-CoV-2 using ddPCR was conducted to provide a framework for understanding noise versus signal when small quantities of amplification appear in a sample. A set of 64 blanks were analyzed to estimate a method detection limit for SARSCoV-2 quantification via ddPCR. The blanks analyzed included nuclease free water (Zymo Research and Invitrogen-Thermo Fisher Scientific) and blank PDMS pads. Method blanks were non-zero $20 \%$ of the time. The estimated MDL, determined to be 6 copies/extraction, was determined by adding three times the standard deviation of the method blanks to their mean concentration.(8) 


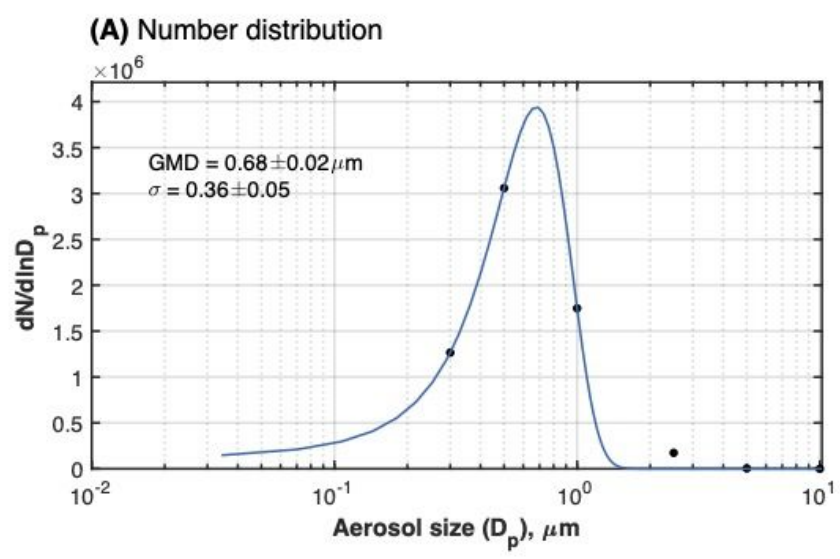

(B) Volume distribution

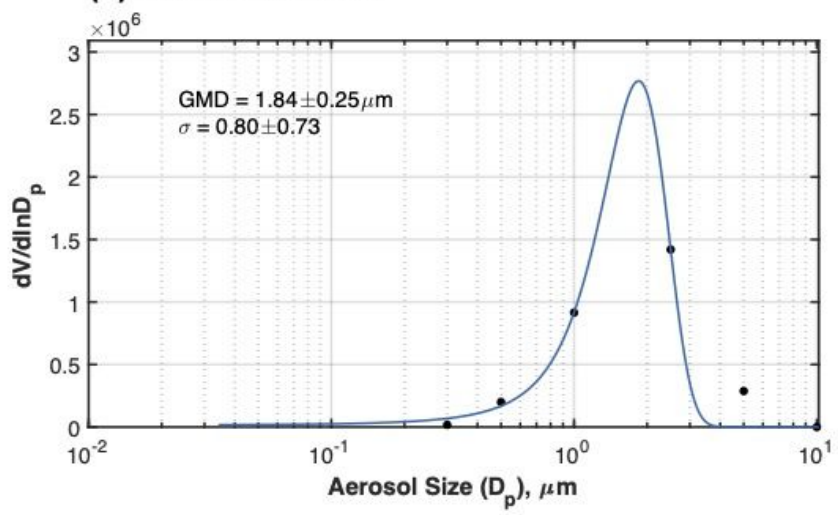

Figure S1. Representative number (A) and volume (B) size distributions of aerosols in the rotating drum. The geometric mean diameters (GMDs) for the particle number and volume distributions were $(0.68 \pm 0.02)$ and $(1.84 \pm 0.25) \mu \mathrm{m}$, respectively.
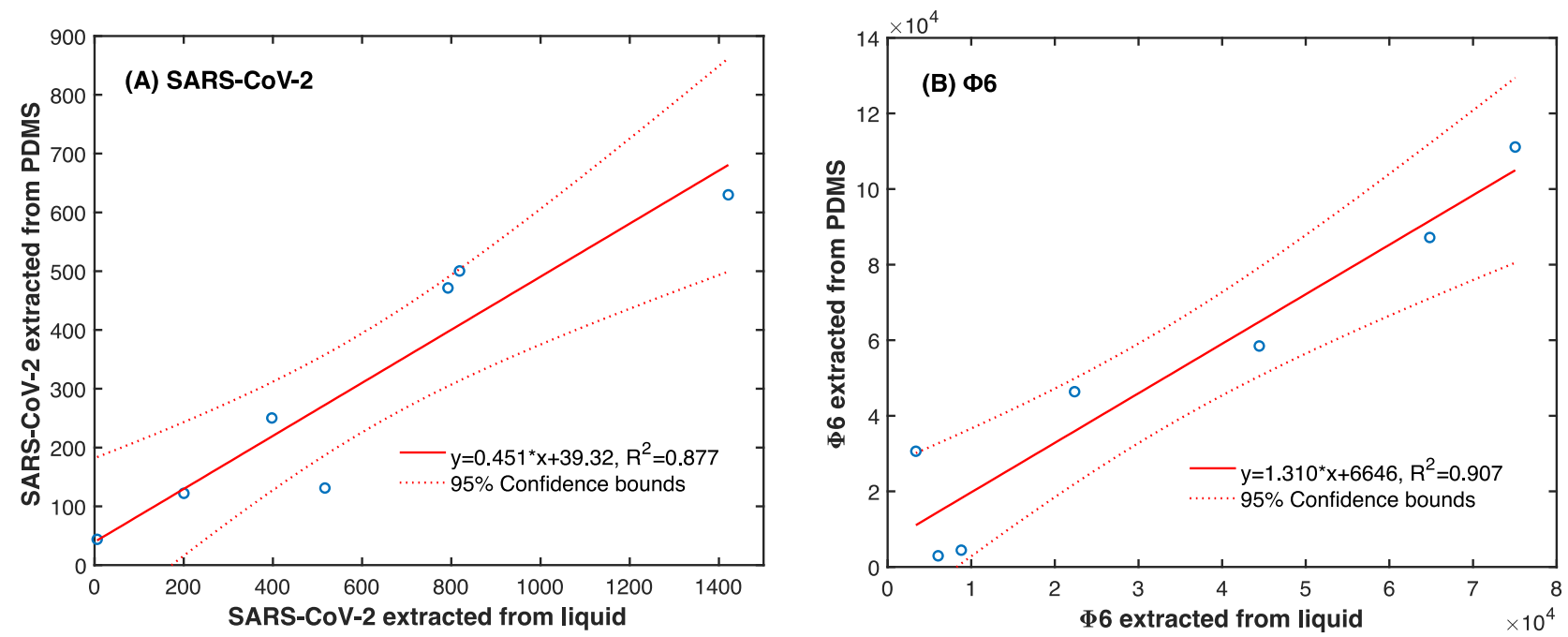

Figure S2. The recovery of SARS-CoV-2 (A) and $\Phi 6$ (B) from PDMS pads. Recovery was determined based on measurement of RNA copies extracted from PDMS and directly in aqueous suspensions. The ranges of RNA amount in tested standards covered the expected RNA ranges of collected samples. 


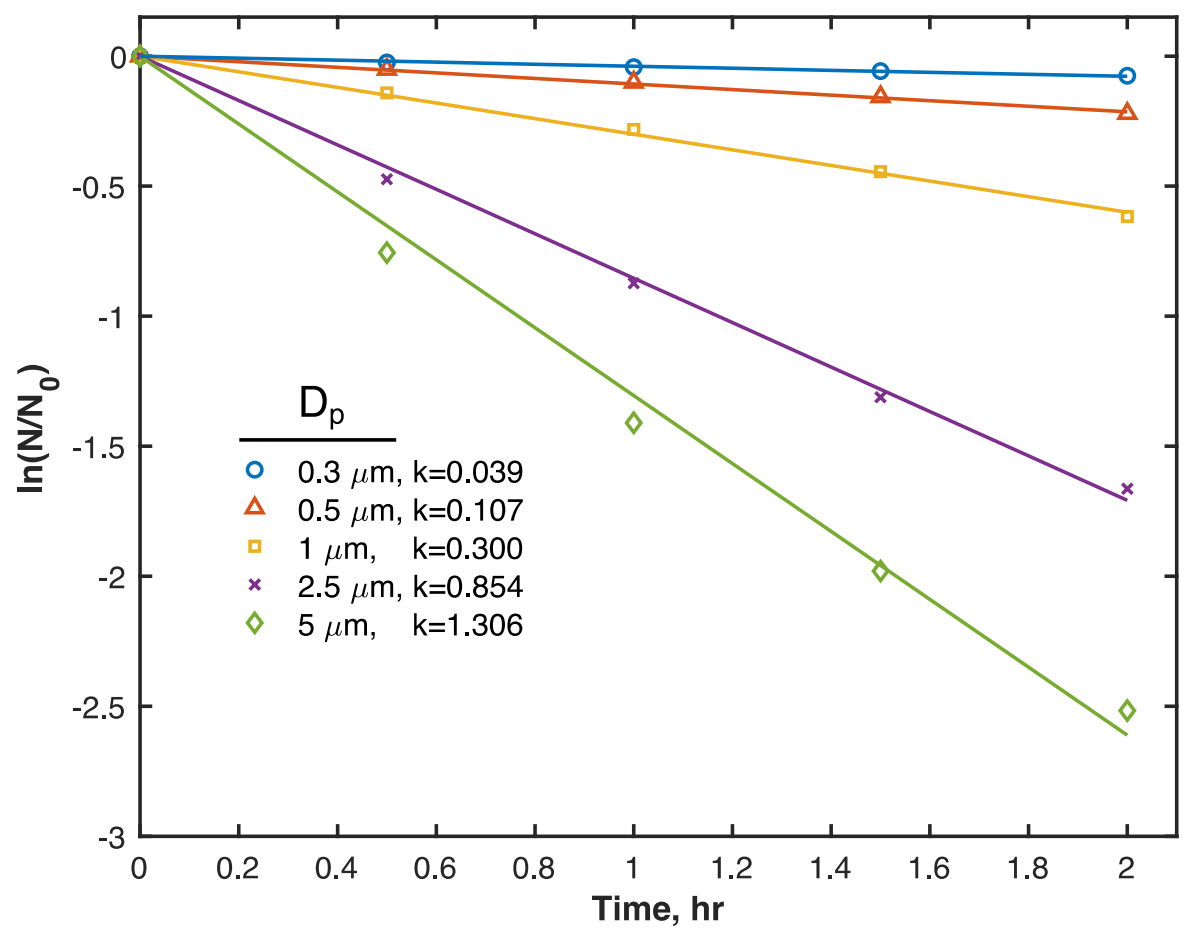

Figure S3. Aerosol decay as a function of time for sizes of $0.3,0.5,1,2.5$, and $5 \mu \mathrm{m}$. Calculated size-fractionated first order decay constants are shown.

197
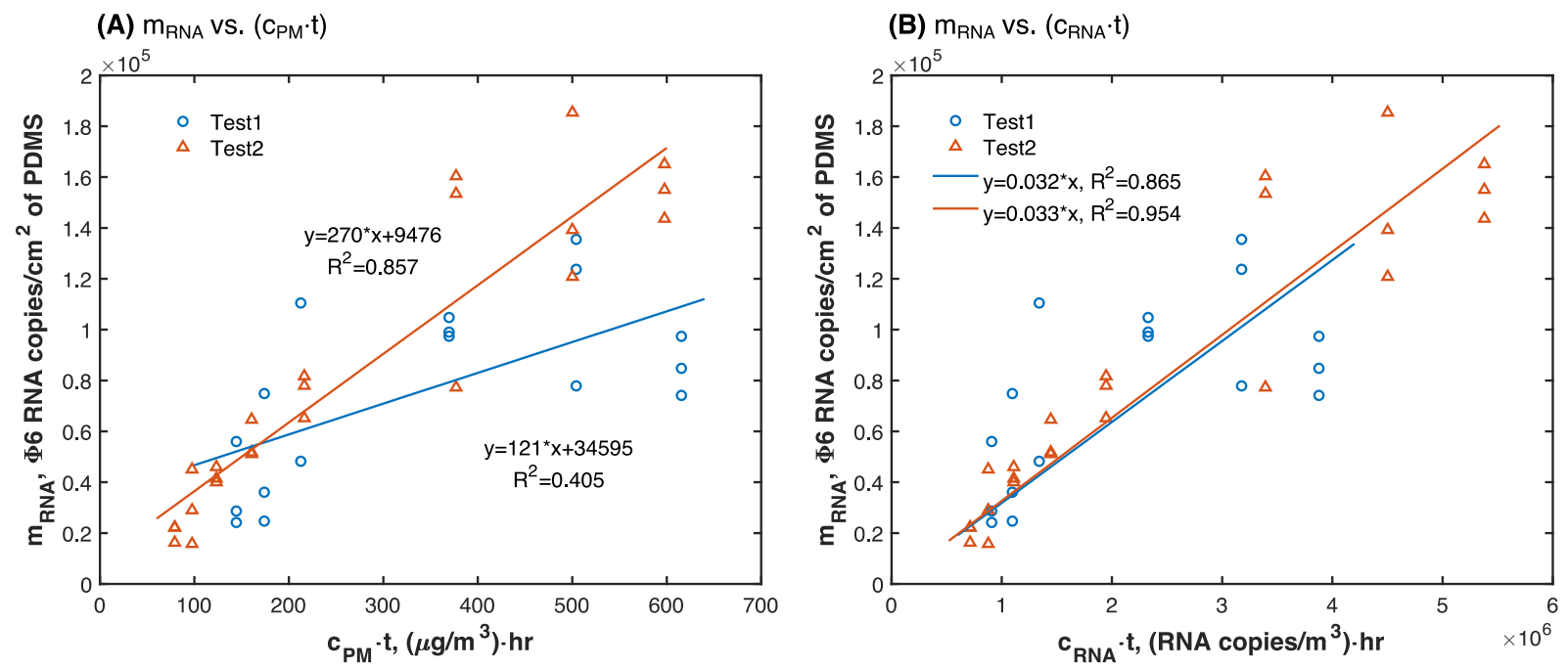

Figure S4. The number of $\Phi 6$ RNA copies collected in per unit area of PDMS after exposure in the rotating drum as a function of cumulative exposure to bulk aerosols (A) and cumulative exposure to $\Phi 6$ (B). All individual replicates instead of the average value for each exposure were used for the regression. 

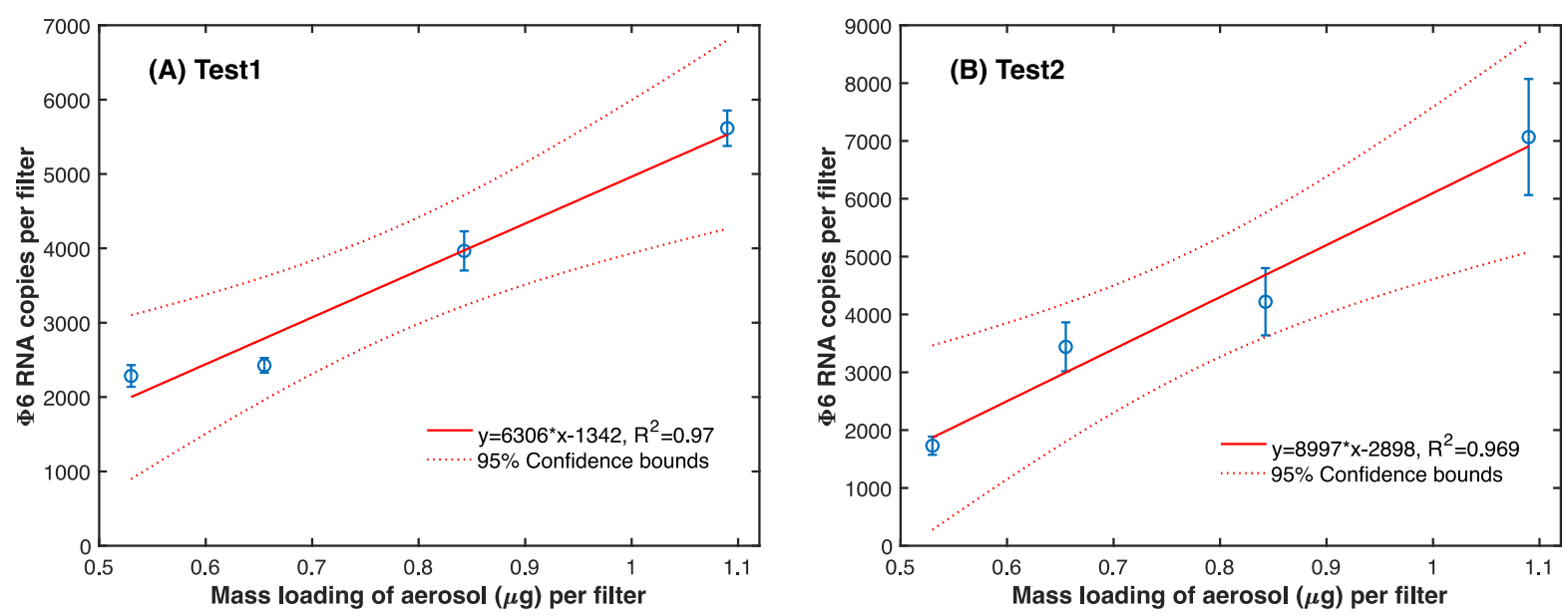

Figure S5. Relationship between number of extracted $\Phi 6$ RNA copies from gelatin filter and the total mass of aerosol collected on gelatin filters. Error bars indicate the measurement uncertainties.

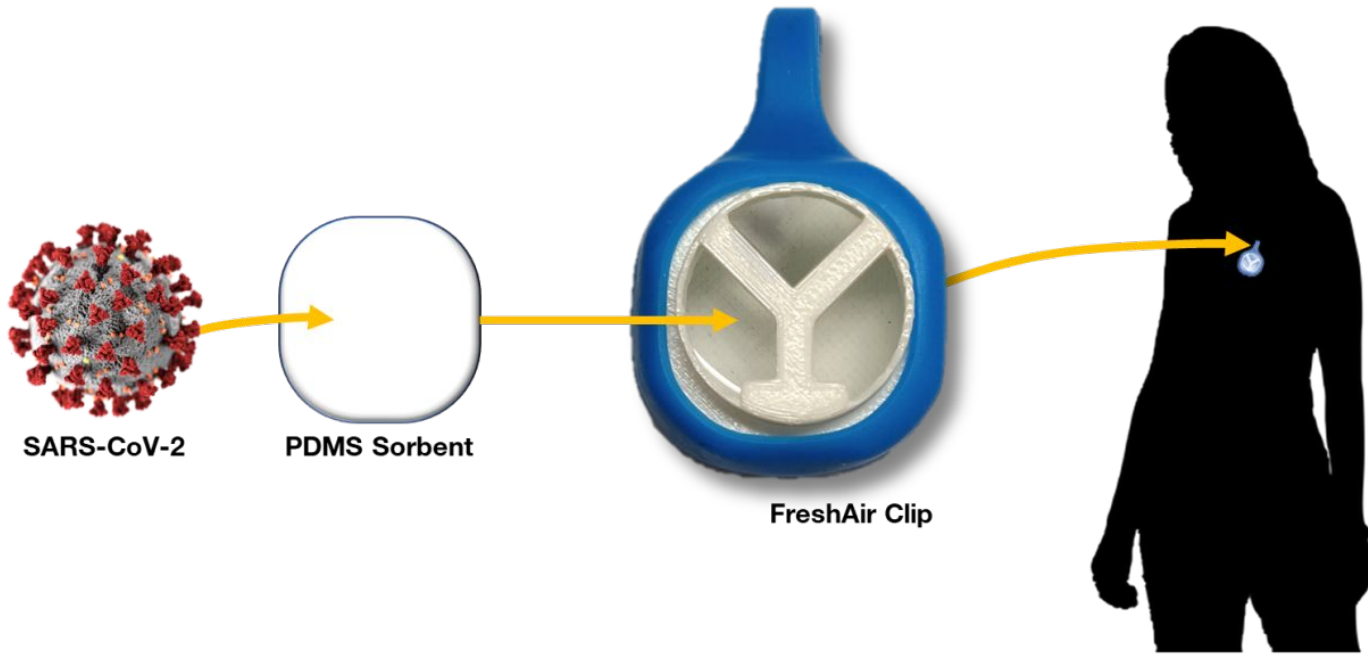

Figure S6. PDMS passive sampler. Viral aerosols and droplets containing SARS-CoV-2 are deposited on the PDMS material inside the Fresh Air Clip, worn on a subject's shirt. 


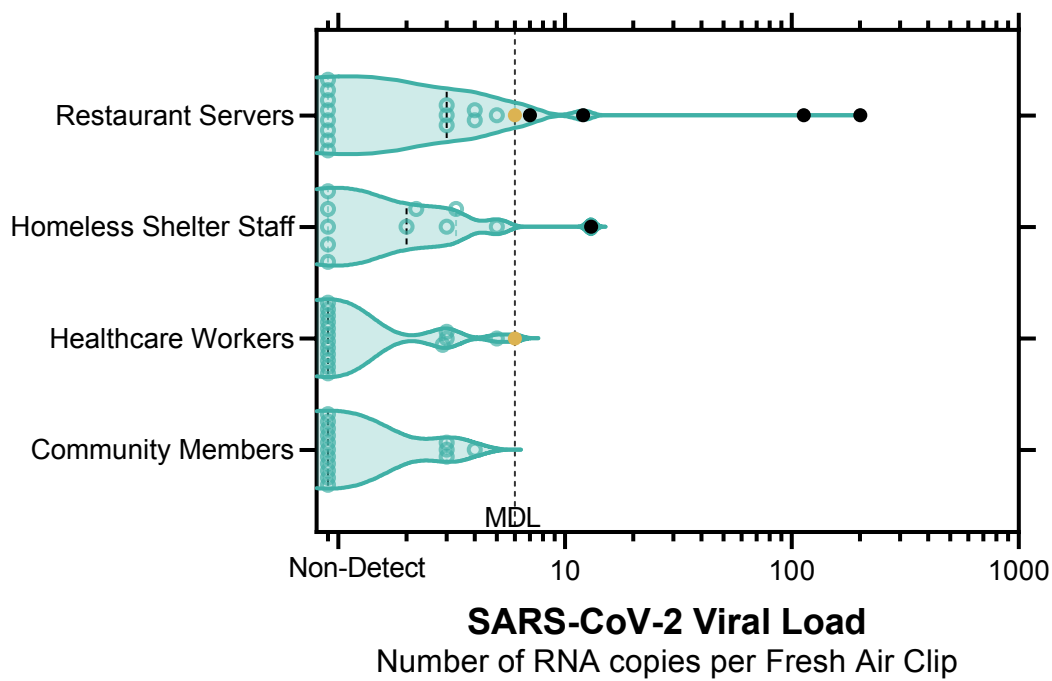

214 Figure S7. Distribution of the amount of SARS-CoV-2 RNA copies present on individual PDMS 215 Fresh Air Clips worn by each participant by sampling location. Black circles indicate samples 216 which were deemed positive for SARS-CoV-2 (above the MDL with both replicates positive), 217 yellow circles depict samples which were above the MDL but only one replicate was positive, 218 thus the sample was not counted as positive for SARS-CoV-2, and the hollow blue samples 219 reported levels of SARS-CoV-2 which fell below the MDL.

221 Table S1. Composition of artificial saliva.(9)

\begin{tabular}{|c|c|c|c|}
\hline Chemical species & Amount & Chemical Species & Amount \\
\hline $\mathrm{MgCl}_{2} \cdot 6 \mathrm{H}_{2} \mathrm{O}$ & $0.04 \mathrm{~g}$ & $\mathrm{KSCN}$ & $0.19 \mathrm{~g}$ \\
\hline $\mathrm{CaCl}_{2} \cdot 2 \mathrm{H}_{2} \mathrm{O}$ & $0.15 \mathrm{~g}$ & $\left(\mathrm{NH}_{2}\right)_{2} \mathrm{CO}$ & $0.12 \mathrm{~g}$ \\
\hline $\mathrm{NaHCO}_{3}$ & $0.42 \mathrm{~g}$ & $\mathrm{NaCl}$ & $0.88 \mathrm{~g}$ \\
\hline $0.2 \mathrm{M} \mathrm{KH}_{2} \mathrm{PO}_{4}$ & $7.7 \mathrm{~mL}$ & $\mathrm{KCl}$ & $1.04 \mathrm{~g}$ \\
\hline $0.2 \mathrm{M} \mathrm{K}_{2} \mathrm{HPO}_{4}$ & $12.3 \mathrm{~mL}$ & Mucin & $3.00 \mathrm{~g}$ \\
\hline $\mathrm{NH}_{4} \mathrm{Cl}$ & $0.11 \mathrm{~g}$ & Water (HPLC grade) & $1000 \mathrm{~mL}$ \\
\hline
\end{tabular}

Table S2. Details of participants' personal exposure to airborne SARS-CoV-2 are shown.

224 Results are limited to samples found to be positive for SARS-CoV-2. Exposures are expressed as 225 viral load, cumulative exposure, and airborne concentrations.

\begin{tabular}{lllll}
\hline $\begin{array}{l}\text { Participants' } \\
\text { Exposure } \\
\begin{array}{l}\text { Assessment } \\
\text { Location }\end{array}\end{array}$ & $\begin{array}{l}\text { SARS-CoV-2 } \\
\text { Viral Load } \\
\text { (RNA copies /clip) }\end{array}$ & $\begin{array}{l}\text { Assessment } \\
\text { Duration } \\
(\mathrm{hr})\end{array}$ & $\begin{array}{l}\text { Cumulative } \\
\text { Exposure to Virus } \\
\left(\left[\mathrm{RNA} \text { copies } \mathrm{m}^{-3}\right] \cdot \mathrm{hr}\right)\end{array}$ & $\begin{array}{l}\text { Airborne Virus } \\
\text { concentration } \\
\left(\text { RNA copies } \mathrm{m}^{-3} \text { ) }\right.\end{array}$ \\
\hline Restaurant & 7 & 30 & 117 & 4 \\
Restaurant & 12 & 30 & 201 & 7 \\
Restaurant & 113 & 30 & 1891 & 63 \\
Restaurant & 200 & 30 & 3347 & 112 \\
Homeless Shelter & 13 & 40 & 218 & 5 \\
\hline
\end{tabular}




\section{REFERENCES}

228 [1] S. Duffy, P.E. Turner, C.L. Burch, Pleiotropic costs of niche expansion in the RNA

229 bacteriophage Phi 6, Genetics 172(2) (2006) 751-757. doi: 10.1534/genetics.105.051136.

230 [2] A.M. Kropinski, A. Mazzocco, T.E. Waddell, E. Lingohr, R.P. Johnson, Enumeration of 231 bacteriophages by double agar overlay plaque assay, Methods Mol Biol 501 (2009) 69-76. doi: 10.1007/978-1-60327-164-6_7.

[3] J.F. de la Mora, D.M. Angel, J. Peccia, How narrow is the gas phase mobility distribution of enveloped viruses? The case of the Phi6 bacteriophage, Analytical Chemistry 93 (2021) 1293812943. doi: 10.1021/acs.analchem.1c02402.

[4] S.H. Huang, Y.M. Kuo, C.W. Lin, W.R. Ke, C.C. Chen, Experimental Characterization of Aerosol Suspension in a Rotating Drum, Aerosol and Air Quanlity Reserach 19 (2019) 688-697. doi: 10.4209/aaqr.2018.05.0174

[5] L. Gendron, D. Verreault, M. Veillette, S. Moineau, C. Duchaine, Evaluation of Filters for the Sampling and Quantification of RNA Phage Aerosols, Aerosol Science and Technology 44(10) (2010) 893-901. doi: 10.1080/02786826.2010.501351.

[6] M.T. Lee, A. Pruden, L.C. Marr, Partitioning of Viruses in Wastewater Systems and Potential for Aerosolization, Environmental Science \& Technology Letters 3(5) (2016) 210-215. doi:

244 10.1021/acs.estlett.6b00105.

[7] N. Turgeon, M.J. Toulouse, B. Martel, S. Moineau, C. Duchaine, Comparison of Five 80(14) (2014) 4242-4250. doi: 10.1128/Aem.00767-14.

[8] US EPA, Definition and Procedure for the Determination of the Method Detection Limit, Revision 2, EPA 821-R-16-006. US EPA: Engineering and Analytical Support Branch/EAD. (Accessed October 3, 2021).

[9] M.H. Woo, Y.M. Hsu, C.Y. Wu, B. Heimbuch, J. Wander, Method for contamination of 252 filtering facepiece respirators by deposition of MS2 viral aerosols, Journal of Aerosol Science 253 41(10) (2010) 944-952. doi: 10.1016/j.jaerosci.2010.07.003. 